\title{
FITOSSANIDADE DA FLORESTA URBANA LINEAR DA RUA ANCHIETA EM JUNDIAÍ-SP, BRASIL
}

\author{
PHYTOSANITARY CONDITION OF THE LINEAR URBAN FOREST FROM ANCHIETA \\ STREET IN JUNDIAÍ-SP, BRAZIL
}

June Ferraz Musselli , Natasha Macias Martinez ${ }^{2}$, Ana Beatriz Carollo Rocha-Lima ${ }^{3}$

\section{RESUMO}

A arborização urbana interfere diretamente na qualidade ambiental das cidades, por isso é de suma importância que as árvores existentes no ambiente urbano sejam frequentemente avaliadas, evitando-se assim remoções desnecessárias ou quedas que podem trazer riscos aos transeuntes e aos bens materiais. Portanto, o principal objetivo do presente estudo foi avaliar o estado fitossanitário das árvores da Rua Anchieta em Jundiaí-SP. Também foram avaliados outros parâmetros correlatos como espécie, largura do passeio, problemas com raiz, conflito com a rede elétrica, circunferência na altura do peito (CAP), diâmetro de copa, altura total, interferência no trânsito e idade estimada. A motivação do presente estudo foi o grande tráfego diário de pessoas e veículos que passam por esse local diariamente. Os resultados obtidos indicam que a maior parte das árvores da Rua Anchieta em Jundiaí-SP encontram-se em estado fitossanitário regular, porém seis indivíduos arbóreos se revelaram bastante deteriorados, indicando uma possível necessidade de remoção.

Palavras-chave: Arborização; Estado fitossanitário; Árvores; Avaliação arbórea; Alameda.

\begin{abstract}
Urban afforestation directly interferes with the environmental quality of cities, so it is extremely important that trees in the urban environment are frequently evaluated, thus avoiding unnecessary removals or falls that can pose risks to passers-by and property. Therefore, the main objective of the present study was to evaluate the phytosanitary status of the trees on Rua Anchieta in Jundiaí-SP. Other related parameters were also evaluated, such as species, sidewalk width, root problems, conflict with the electrical network, circumference at breast height $(\mathrm{CBH})$, crown diameter, total height, traffic interference and estimated age. The motivation of this study was the large daily traffic of people and vehicles passing by this place every day. The results obtained indicate that most of the trees on Rua Anchieta in Jundiaí-SP are in regular phytosanitary condition, however, six arboreal individuals proved to be quite deteriorated, indicating a possible need for removal.
\end{abstract}

Keywords: Urban afforestation; Phytosanitary status; Trees; Plant health evaluation; Avenue.

Recebido em 26.07.2020 e aceito em 03.12.2020

1 Bióloga. Curso de Ciências Biológicas, Instituto de Ciências da Saúde. Universidade Paulista - UNIP, campus Jundiaí. Jundiaí/SP. Email: june_musselli@hotmail.com

2 Bióloga. Curso de Ciências Biológicas, Instituto de Ciências da Saúde. Universidade Paulista - UNIP, campus Jundiaí. Jundiaí/SP. Email: natasha.macias@hotmail.com

3 Bióloga. Mestre em Biologia Animal. Professora da Universidade Paulista - UNIP, campus Jundiaí. Jundiaí/SP. Email: abeatrizcrl@gmail.com 


\section{INTRODUÇÃO}

A arborização urbana diz respeito à vegetação que compõe a paisagem de uma cidade e inclui as árvores presentes em vias públicas, parques, bosques, praças e jardins. A arborização colabora para a obtenção de um ambiente urbano mais agradável, interferindo na qualidade de vida nas cidades e, consequentemente, na saúde da população (PINHEIRO; DE SOUZA, 2017). Diante do rápido crescimento das cidades, o planejamento adequado na implantação da arborização viária foi deixado de lado. A má distribuição e acomodação das árvores pode ocasionar o crescimento desordenado de suas raízes e galhos gerando rachaduras nas calçadas e, consequentemente, dificuldades de locomoção (SZABO, 2017).

É essencial conhecer as características de cada espécie e as condições do meio onde se dará o plantio para que, ao longo do tempo, não ocorram situações desagradáveis que poderão gerar a necessidade de manutenção ou remoção destas. A arborização urbana deve levar em conta muitos fatores como, por exemplo, a presença de fiações e instalações subterrâneas (água, luz, telefone, esgoto, gás); a largura das ruas (para o planejamento da altura e extensão das copas de maneira a não interferir no tráfego); a largura dos passeios (onde as árvores serão plantadas); o tráfego de pedestres e veículos; a altura das marquises (para a implantação de espécies com porte adequado), entre outros (SZABO, 2017).

Outro fator importante no planejamento da arborização urbana é a escolha das espécies que vão compor a paisagem. É recomendado que se utilizem espécies nativas que ocorram naturalmente na região, pois assim, elas não serão submetidas a condições diferentes de seu ambiente natural, o que comprometeria o seu crescimento, adaptabilidade e desenvolvimento. (MUNEROLI; MASCARÓ, 2010). A heterogeneidade na composição das espécies é outro ponto importante, pois protege a flora nativa, além de favorecer a sobrevivência de animais possibilitando, então, um equilíbrio ecológico (TOLEDO; PARENTE, 1988).

Diante da importância da arborização urbana, é extremamente necessário que se avaliem os indivíduos já implantados a fim de se conhecer seu estado fitossanitário. Uma avaliação detalhada permite a detecção de problemas que poderiam levar o indivíduo arbóreo à queda, causando prejuízos materiais ou até mesmo a morte de pessoas. Caso seja feita uma avaliação constante, é possível que alguns problemas possam ser detectados no início e que intervenções ainda sejam viáveis, prolongando a vida do indivíduo arbóreo e evitando que este precise ser suprimido.

Portanto, o objetivo geral do presente estudo foi realizar a avaliação dos aspectos dendrométricos, físicos e fitossanitários das árvores presentes na Rua Anchieta em Jundiaí-SP. 


\section{MATERIAL E MÉTODOS}

A rua Anchieta, no município de Jundiaí, foi selecionada para realização desta pesquisa, pois se trata de uma via bastante arborizada, com sobreposição de copas ao longo de 700 metros (Figuras 1a e 1b), e apresenta um grande tráfego de pessoas e veículos por conta dos inúmeros edifícios que prestam serviços de saúde (consultórios médicos, laboratórios etc.). Portanto, a possível queda de uma árvore neste local poderia provocar sérios ferimentos nos transeuntes e causar danos a imóveis e veículos.

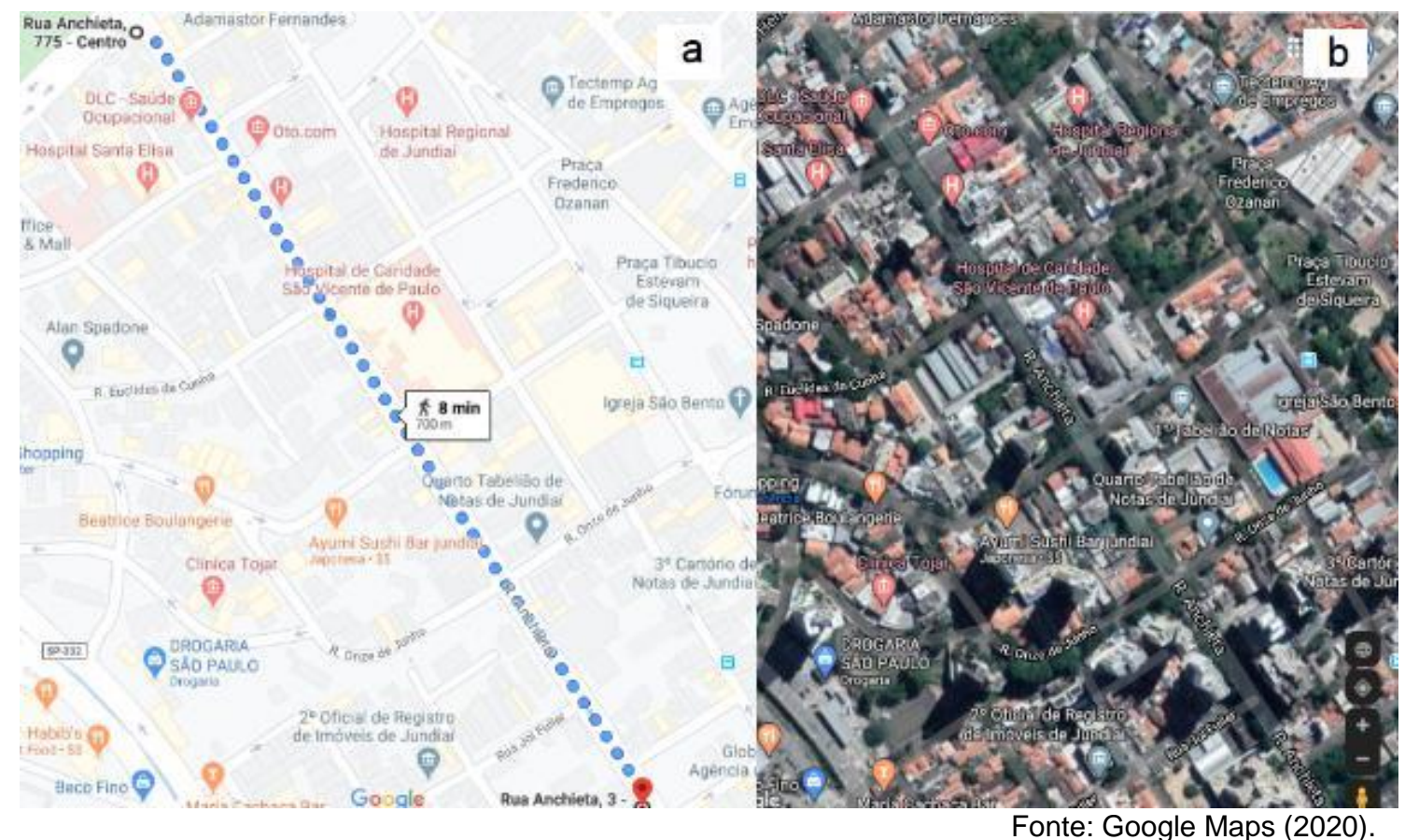

Figura 1. Mapa da Rua Anchieta em Jundiaí-SP: a) destaque ao comprimento da rua e b) destaque à arborização linear com sobreposição de copas

Figure 1. Map of Rua Anchieta in Jundiaí-SP: a) emphasis on the length of the street and b) emphasis on linear afforestation with overlapping tree crowns

O presente estudo realizou um levantamento dos aspectos de fitossanidade das árvores presentes Rua Anchieta em Jundiaí-SP. A metodologia utilizada foi a mesma do Plano Municipal de Arborização Urbana do município de Cabreúva-SP (CABREÚVA, 2017). Foi feita a identificação da espécie através da bibliografia especializada (LORENZI et al., 2003, LORENZI, 2002) e também foram avaliados aspectos como a largura do passeio onde está localizado o indivíduo arbóreo, possíveis problemas com raiz, conflitos com a rede elétrica, circunferência na altura do peito (CAP), diâmetro de copa, altura total, interferência no trânsito e idade estimada a fim de se diagnosticar o estado fitossanitário de cada um dos indivíduos arbóreos identificados. 
O levantamento dos dados foi realizado nos dias 15 e 26 de agosto de 2019. O levantamento foi realizado a partir de uma planilha contendo todos os parâmetros citados acima e uma legenda numérica para facilitar a coleta das informações em campo (Tabela 1).

Tabela 1. Legenda numérica utilizada para preencher a tabela de parâmetros Table 1. Numeric legend used to fill the parameter table

\begin{tabular}{|c|c|c|c|c|c|c|}
\hline Legenda & Parâmetro & 1 & 2 & 3 & 4 & 5 \\
\hline FITO & $\begin{array}{c}\text { Estado } \\
\text { fitossanitário }\end{array}$ & Morta & Ruim & Regular & Boa & Condenada \\
\hline LARPAS & $\begin{array}{l}\text { Largura do } \\
\text { passeio }\end{array}$ & $\begin{array}{c}\text { Ausência de } \\
\text { Passeio }\end{array}$ & 0 a $1,5 \mathrm{~m}$ & 1,5 a $3,0 \mathrm{~m}$ & $\begin{array}{c}\text { Superior } \\
\text { a } 3,0 \mathrm{~m}\end{array}$ & -- \\
\hline PRAIZ & $\begin{array}{l}\text { Problemas } \\
\text { com raiz }\end{array}$ & Não Apresenta & Aponta & Quebra & Destrói & -- \\
\hline CONFIA & $\begin{array}{l}\text { Conflito com } \\
\text { fiação elétrica }\end{array}$ & Fiação Ausente & Interfere & $\begin{array}{c}\text { Vai } \\
\text { Interferir }\end{array}$ & -- & -- \\
\hline CAP & $\begin{array}{l}\text { Circunferência na } \\
\text { altura do peito }\end{array}$ & $1-60 \mathrm{~cm}$ & $\begin{array}{c}61- \\
120 \mathrm{~cm}\end{array}$ & $121-200 \mathrm{~cm}$ & $\begin{array}{c}201- \\
500 \mathrm{~cm}\end{array}$ & -- \\
\hline DIACO & Diâmetro de copa & Até $4 \mathrm{~m}$ & 4 a $7 m$ & $7 a \mathrm{a} 10 \mathrm{~m}$ & 10 a $15 \mathrm{~m}$ & $\begin{array}{l}\text { Superior } \\
\text { a } 15 \mathrm{~m}\end{array}$ \\
\hline ALTOT & Altura total & Até $5 \mathrm{~m}$ & 5 a $10 m$ & 10 a $15 \mathrm{~m}$ & $\begin{array}{l}\text { Superior } \\
\text { a } 15 \mathrm{~m}\end{array}$ & -- \\
\hline INTRAN & $\begin{array}{l}\text { Interferência } \\
\text { no trânsito }\end{array}$ & Não Interfere & $\begin{array}{l}\text { Interfere } \\
\text { Pedestres }\end{array}$ & $\begin{array}{l}\text { Interfere } \\
\text { Veículos }\end{array}$ & $\begin{array}{c}\text { Interfere } \\
\text { Pedestres } \\
\text { e Veículos }\end{array}$ & -- \\
\hline IDADE & $\begin{array}{c}\text { Idade } \\
\text { presumida }\end{array}$ & Até 10 anos & $\begin{array}{c}10 \text { a } 30 \\
\text { anos } \\
\text { Sai por }\end{array}$ & $\begin{array}{l}\text { Superior a } \\
30 \text { anos }\end{array}$ & encus & -- \\
\hline RECOM & Recomendação & Fica & $\begin{array}{c}\text { problemas } \\
\text { fitossanitár } \\
\text { ios }\end{array}$ & -- & -- & -- \\
\hline
\end{tabular}

Nota: Adaptada do Plano Municipal de Arborização de Cabreúva (CABREÚVA, 2017)

Foi realizada a avaliação das árvores tanto visualmente como através de instrumentos de diagnóstico como trena, marreta e uma haste de metal que era inserida nas cavidades presentes a fim de verificar sua profundidade (Figura 1).

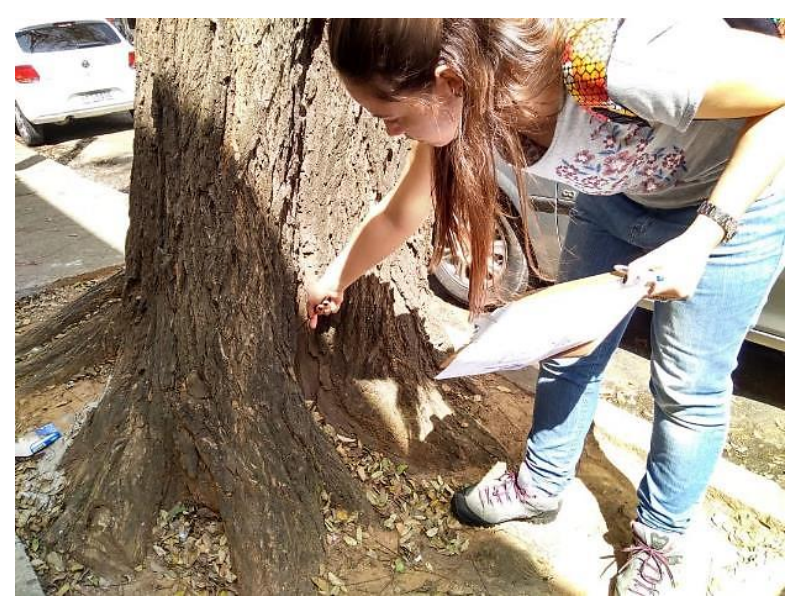

Figura 2. Verificação da profundidade de cavidade presente em indivíduo arbóreo

Figure 2. Verification of the depth of the cavity present in the arboreal individual 


\section{RESULTADOS E DISCUSSÃO}

O presente estudo revelou uma quantidade total de 80 indivíduos arbóreos na Rua Anchieta (107 indivíduos $/ \mathrm{km}$ ). Outros estudos avaliaram a densidade arbórea por km em áreas urbanas e encontraram valores muito inferiores ao presente estudo. Um estudo realizado no município de Registro-SP identificou 37 indivíduos/km (FERRAZ, 2012). Outro estudo realizado no município de Senador Guiomard-AC identificou apenas 6,2 indivíduos/km (MARANHO et al., 2012). Outro estudo realizado no bairro de Petrópolis, em Natal-RN, identificou um índice de 70 indivíduos/km de via percorrida (DOS SANTOS; LISBOA; DE CARVALHO, 2012). Dessa forma, podemos concluir que a densidade arbórea identificada na Rua Anchieta é bastante elevada.

Dos 80 indivíduos arbóreos, 65 (81,25\%) eram Tipuana (Tipuana tipu) (Benth.) Kuntze, 11 (13,75\%) Sibipiruna (Poincianella pluviosa var. peltophoroides) (Benth.) LPQueiroz, 1 (1,25\%) Ficus (Ficus benjamina L.), 1 (1,25\%) Mulungu (Erythrina mulungu) Benth.,1 (1,25\%) Quaresmeira (Tibouchina granulosa) (Desr.) Cogn. e 1 (1,25\%) Ligustro (Ligustrum lucidum) WT Aiton (Figura 3).

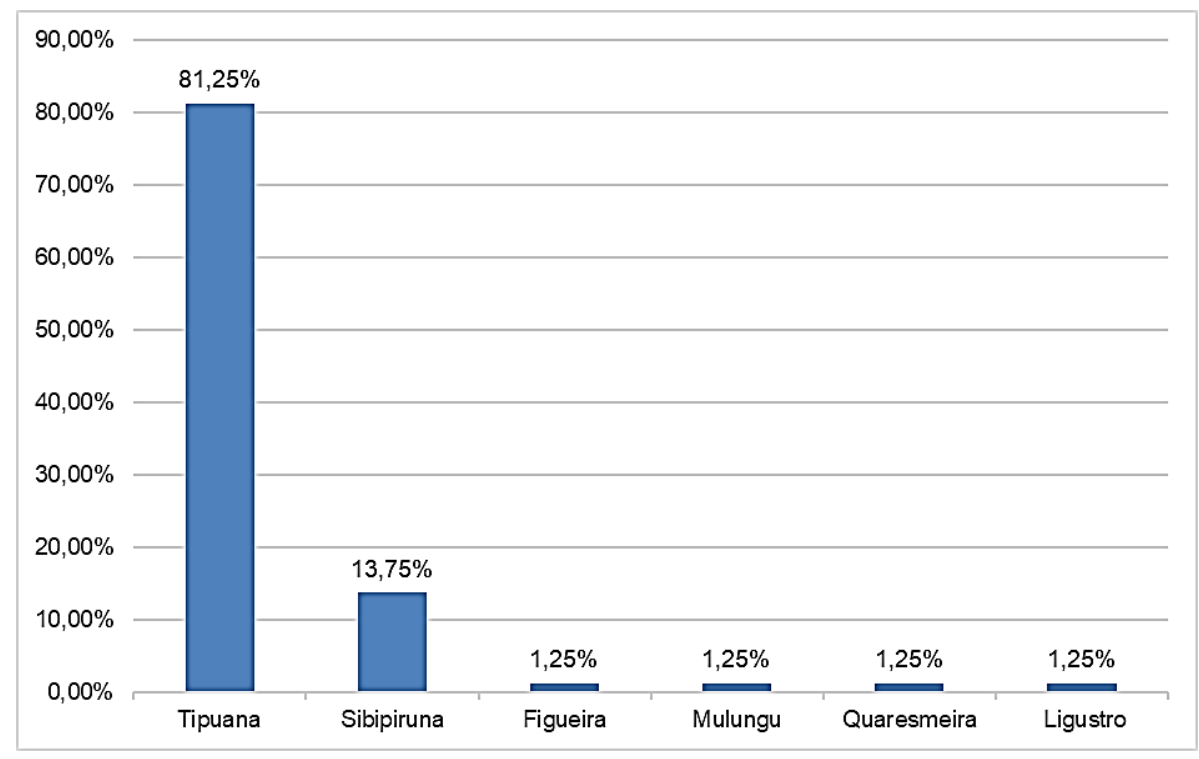

Figura 3. Distribuição das espécies arbóreas Figure 3. Distribution of tree species

Diante dos resultados obtidos, foi possível identificar que as duas espécies de árvores mais presentes na Rua Anchieta são a Tipuana tipu e Poincianella pluviosa var. peltophoroides. A Rua Anchieta é arborizada com árvores da espécie Tipuana tipu há mais de 60 anos, que permitiu que formassem um túnel na rua, proporcionando sombra em toda a sua extensão. (JUNDIAÍ, 2018).

A Tipuana tipu é nativa da Bolívia e Argentina e pertence à família Fabaceae. Ela é amplamente utilizada para a arborização urbana no Brasil, principalmente no Sul e no Sudeste 
desde o século $\mathrm{XX}$, pois proporciona grande sombra e possui flores amarelas com aspecto ornamental, porém o manejo incorreto facilita a ação de fungos e insetos (principalmente cupins) que degradam o lenho, possibilitando a queda de galhos. Ademais, suas raízes danificam as calçadas, dificultando a passagem das pessoas (LORENZI et al., 2003; BRANZOLIN et al., 2014).

Em relação à presença de Tipuana tipu na arborização brasileira, é importante enfatizar que a inserção de plantas exóticas é apontada como a segunda maior ameaça à conservação da biodiversidade mundial, ficando atrás somente da destruição de hábitat devido à exploração humana (ZILLER, 2001).

A segunda espécie mais frequente Poincianella pluviosa, apesar de ser de grande porte, é nativa do Brasil e não possui raízes agressivas às calçadas se plantada adequadamente. Além disso, também possuem flores de coloração amarela durante a primavera e início do verão, fornecendo uma bela aparência às ruas (TOSCAN et al., 2010).

O presente estudo demonstrou ainda que 40 indivíduos (50\%) encontram-se em condições regulares de fitossanidade, 24 indivíduos (30\%) encontram-se em condições ruins, 10 indivíduos (12,5\%) encontram-se em boas condições, 6 indivíduos (7,5\%) encontram-se condenados e nenhum indivíduo arbóreo estava morto (Figura 4).

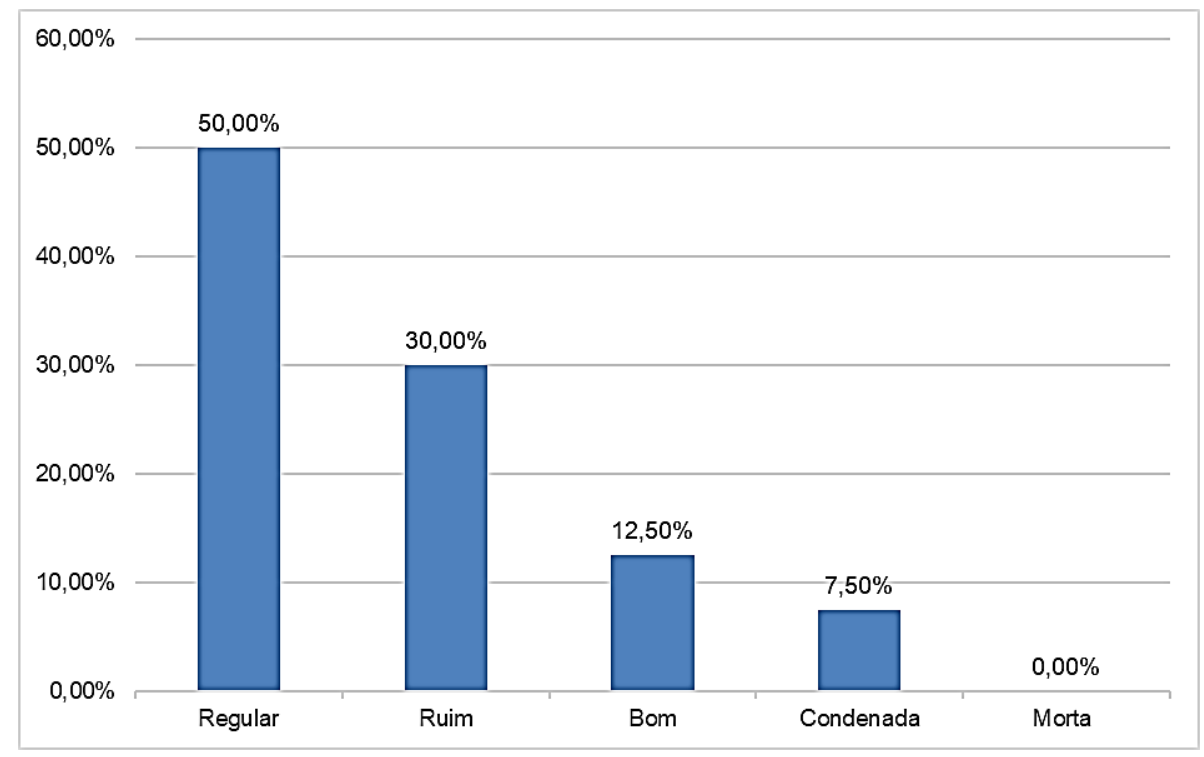

Figura 4. Estado fitossanitário

Figure 4. Phytosanitary status

Mais da metade dos indivíduos arbóreos da Rua Anchieta (50 indivíduos - 62,5\%) encontra-se em condições boas ou regulares de fitossanidade, enquanto $30 \%$ encontram-se em condições ruins e $8 \%$ estão condenados. Muitas árvores apresentavam problemas bastante severos e visíveis, como cavidades presentes no caule (Figura 5), insetos e plantas parasitas. 


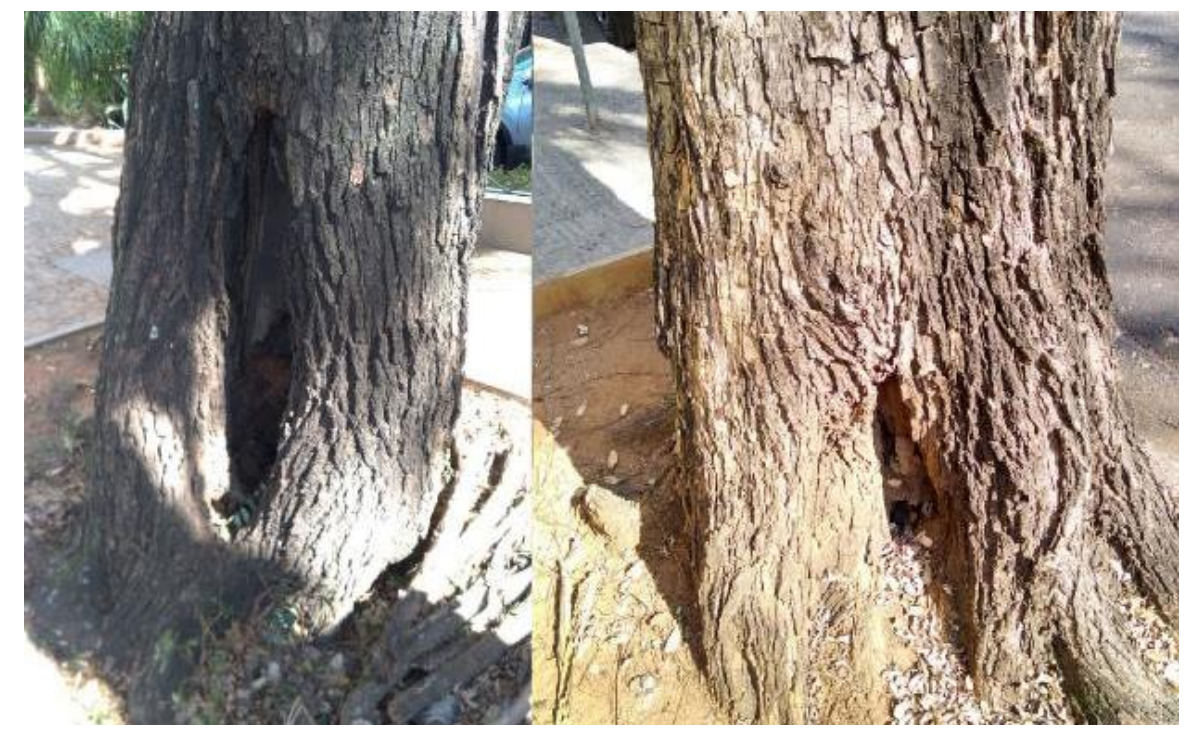

Figura 5. Cavidade presente no caule de dois indivíduos arbóreos

Figure 5. Cavity present in the stem of two tree individuals

Em comparação a outro estudo em que a maior parte das árvores se encontrava em bom estado fitossanitário (CABREÚVA, 2017), é possível perceber que as árvores da Rua Anchieta em Jundiaí-SP encontram-se, de forma geral, em condições bastante ruins, pois somente um pequeno número de indivíduos encontra-se em plenas condições fitossanitárias.

O levantamento demonstrou que $70(87,5 \%)$ dos indivíduos arbóreos estão em locais com passeio entre 1,5 a 3,0m e 10 (12,50\%) em locais com passeio superior a 3,0m (Figura 6).

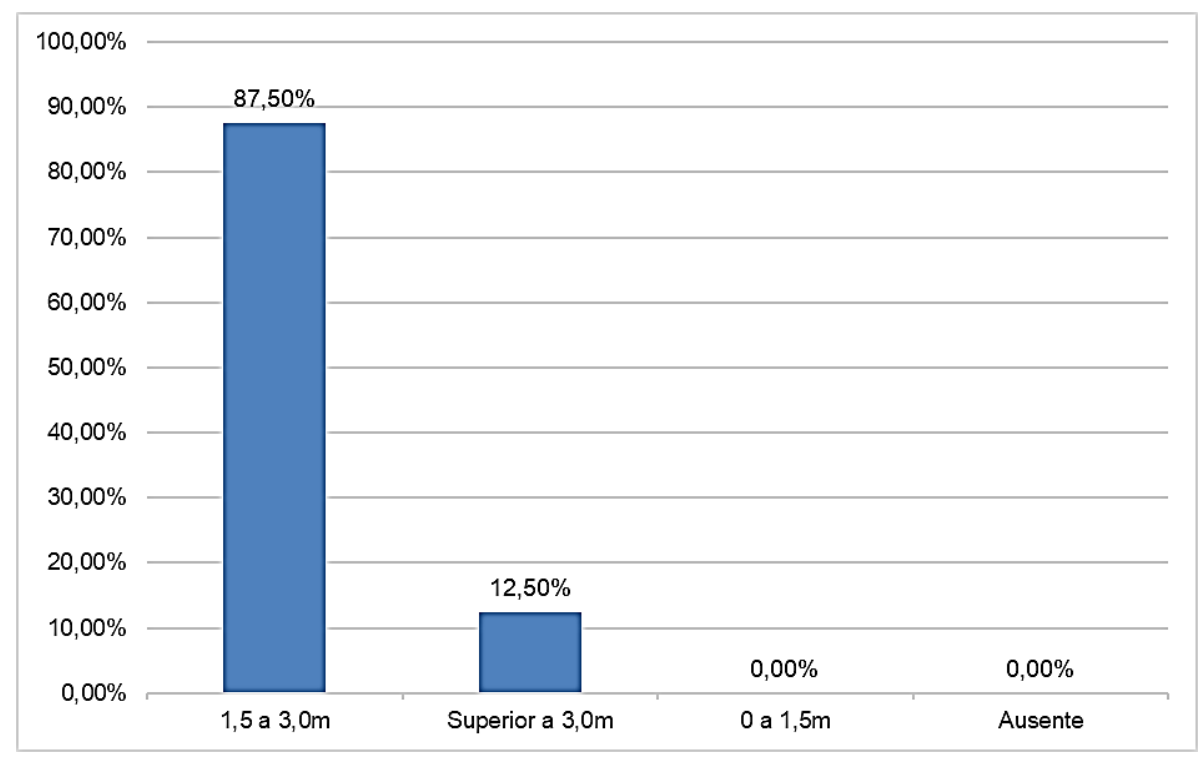

Figura 6. Largura do passeio

Figure 6. Sidewalk width

O levantamento demonstrou que toda a extensão da rua possui passeio com largura acima de 1,5 m, de modo que nenhum indivíduo arbóreo estava interferindo no trânsito de 
veículos ou de pedestres. A largura das calçadas na Rua Anchieta em Jundiaí-SP não é um fator determinante para a remoção de árvores ou o impedimento de novos plantios, pois estas dispõem de espaço suficiente para uma boa acomodação das árvores sem impedir o tráfego dos pedestres. Esse parâmetro se diferencia do levantamento mostrado no "Plano Municipal de Arborização Urbana do município de Cabreúva-SP" o qual mostra que diversos locais possuíam passeios muito estreitos que inviabilizam o plantio de árvores (CABREÚVA, 2017).

Os resultados do presente levantamento mostram ainda que $100 \%$ dos indivíduos arbóreos do local não interferem no trânsito da rua (Figura 7).

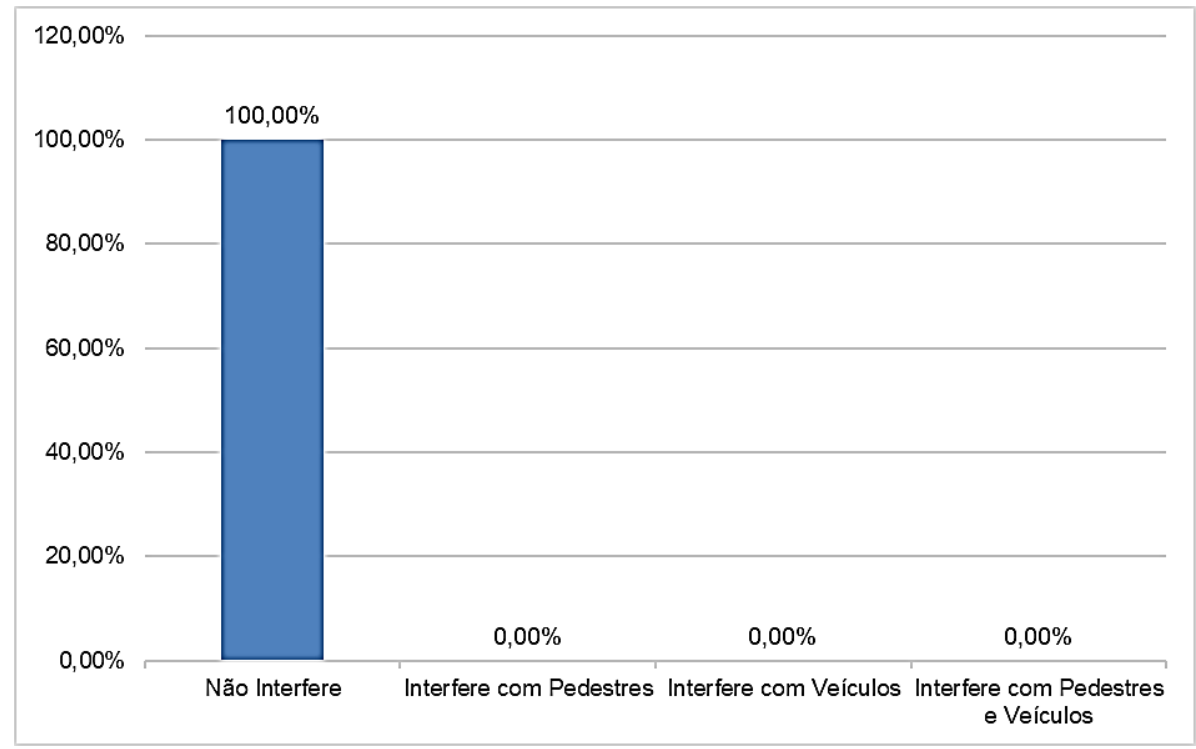

Figura 7. Interferência com o trânsito

Figure 7. Traffic interference

Este parâmetro foi o único que não apresentou problemas, fato este possivelmente decorrente de uma poda recentemente realizada pela Prefeitura de Jundiaí, na qual os galhos mais baixos, com risco de queda e que atrapalhavam a iluminação foram podados (JUNDIAí, 2018). Esse resultado se assemelha ao "Plano Municipal de Arborização Urbana do município de Cabreúva-SP", no qual consta que poucas árvores estavam em conflito com o trânsito e, quando estavam, essa interferência poderia ser resolvida através de podas de condução do indivíduo arbóreo (CABREÚVA, 2017).

Das árvores analisadas, 32 (40\%) apresentam raízes apontando, 22 (27,5\%) quebram a calçada, 15 (18,75\%) destroem a calçada e somente $11(13,75 \%)$ não apresentam problemas (Figura 8). 


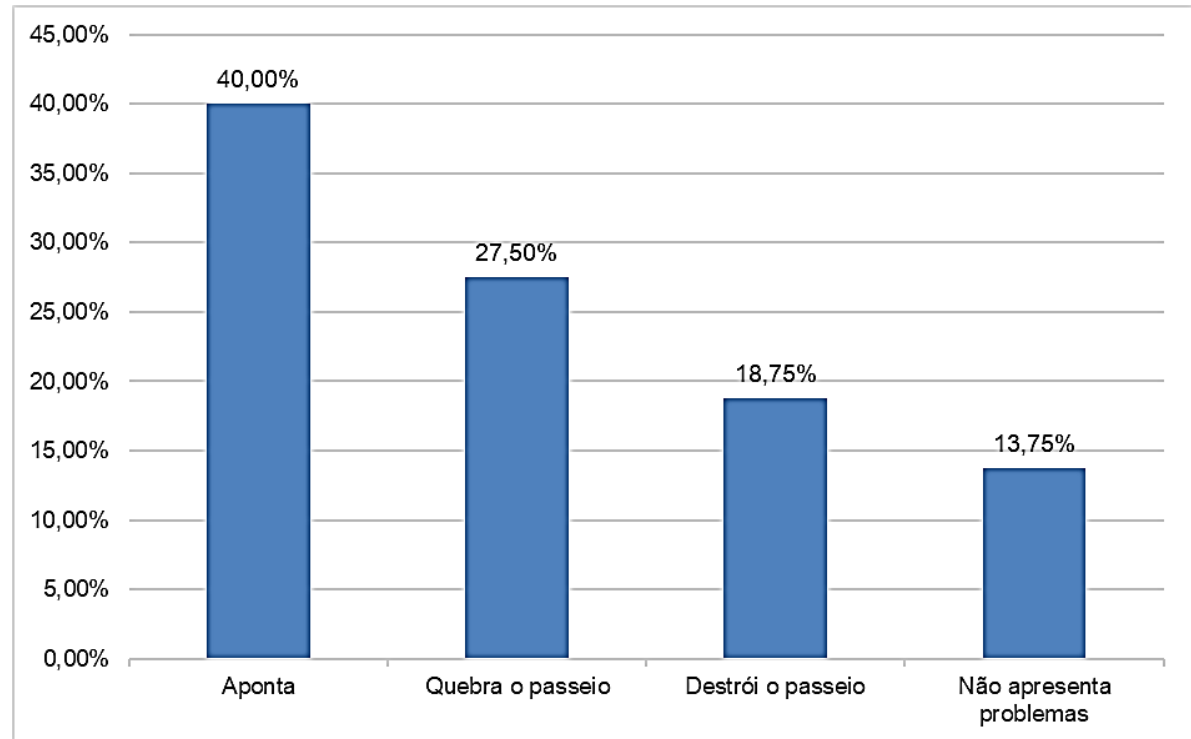

Figura 8. Problemas na raiz

Figure 8. Root problems

O levantamento em campo mostrou que as raízes de 69 dos 80 indivíduos arbóreos $(86,25 \%)$ estão danificando as calçadas (Figura 9).

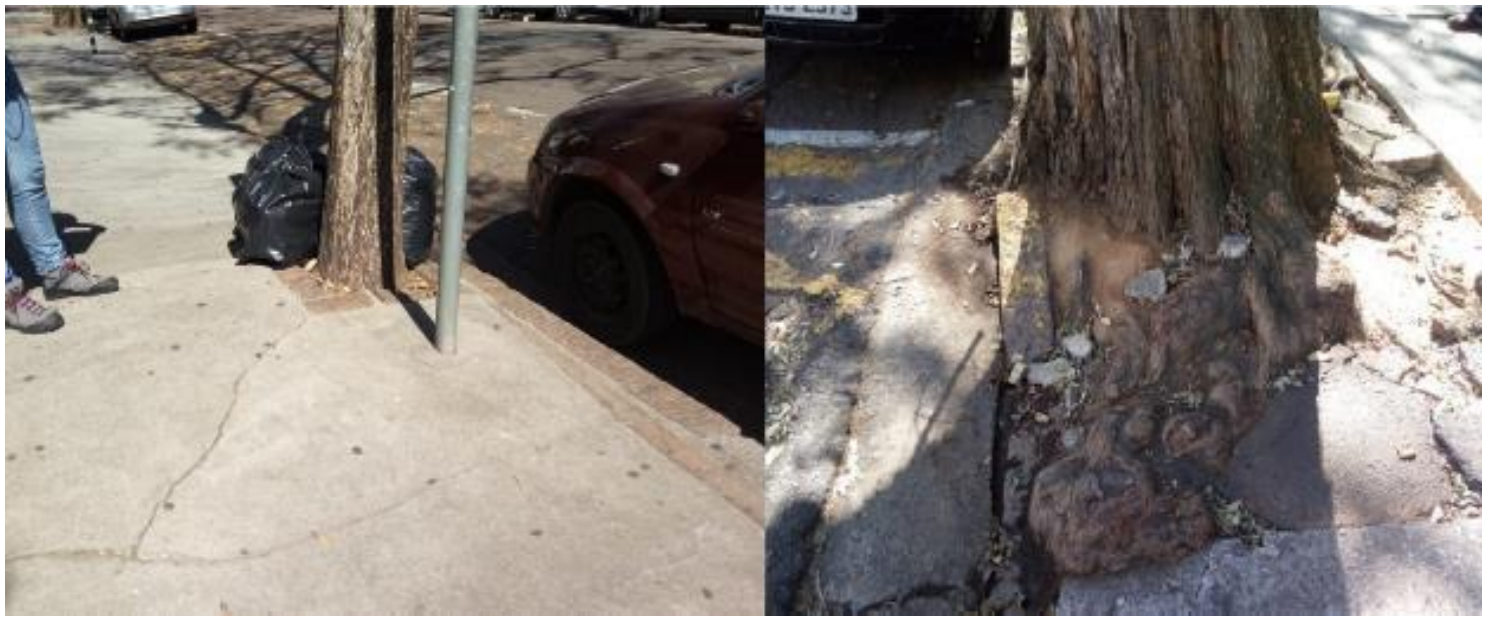

Figura 9. Raízes de dois indivíduos arbóreos quebrando e destruindo a calçada, respectivamente Figure 9. Roots of two tree individuals breaking and destroying the sidewalk, respectively

Devido principalmente à ação antrópica, as raízes das árvores de Tipuana tipu se desenvolvem de maneira inadequada, tornando-se enoveladas e dobradas, fato este que pode levar a árvore ao declínio (BRAZOLIN, 2014). O presente estudo mostrou que este fato é uma realidade bastante presente na Rua Anchieta, na qual a maior parte das raízes, por não ter local apropriado para seu desenvolvimento, acaba crescendo de maneira errônea, tornando-se enovelada (prejudicando a fixação do indivíduo ao solo) e rachando ou destruindo as calçadas. 
Outro parâmetro analisado neste estudo foi o conflito com a rede elétrica, o qual indicou que a maior parte dos indivíduos arbóreos, especificamente 42 indivíduos (52,5\%), estão interferindo na rede elétrica, 13 indivíduos $(16,25 \%)$ irão interferir futuramente devido ao seu porte e localização e 25 indivíduos (31,25\%) não irão interferir, pois estão em locais com ausência de fiação (Figura 10).

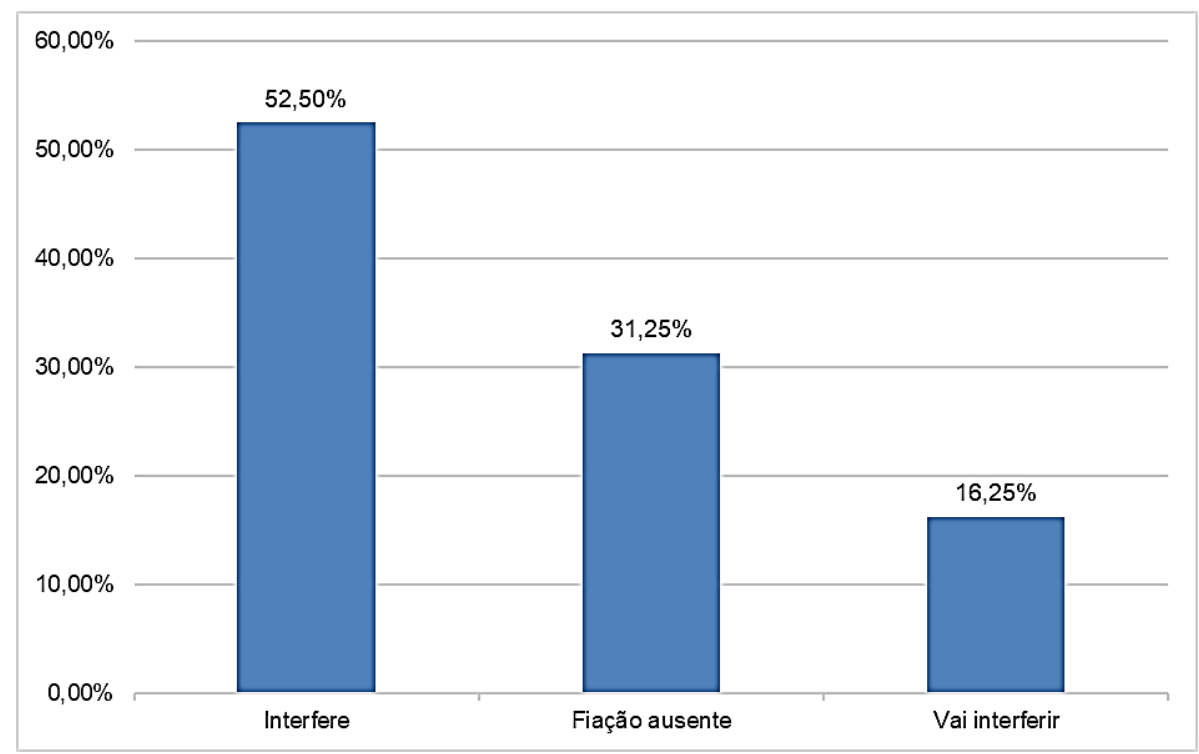

Figura 10. Conflito com a fiação

Figure 10. Conflict with the wiring

O conflito com a rede elétrica foi outro fator problemático identificado no presente estudo. A maior parte dos indivíduos arbóreos interferem ou irão interferir futuramente na rede elétrica devido ao seu porte e localização situada logo abaixo da fiação. Apenas cerca de 1/3 dos indivíduos arbóreos estão em locais com ausência de fiação (Figura 11).

Esta situação é semelhante no estudo "Inventário e análise da arborização do bairro Vila Yolanda, do município de Foz do Iguaçu-PR". Este conflito se deve às grandes dimensões (diâmetro da copa e altura) desses indivíduos. Nos dois trabalhos detectou-se que não houve uma escolha adequada das espécies arbóreas que foram plantadas no local, sendo elas de grande porte e que, consequentemente, interferem ou vão interferir na rede elétrica. Nesses casos, seria necessário um planejamento mais efetivo para evitar uma intervenção desnecessária como uma poda drástica ou, caso o indivíduo já apresente outros problemas, sua supressão e substituição por um indivíduo de uma espécie mais apropriada para o local (TOSCAN et al., 2010). 


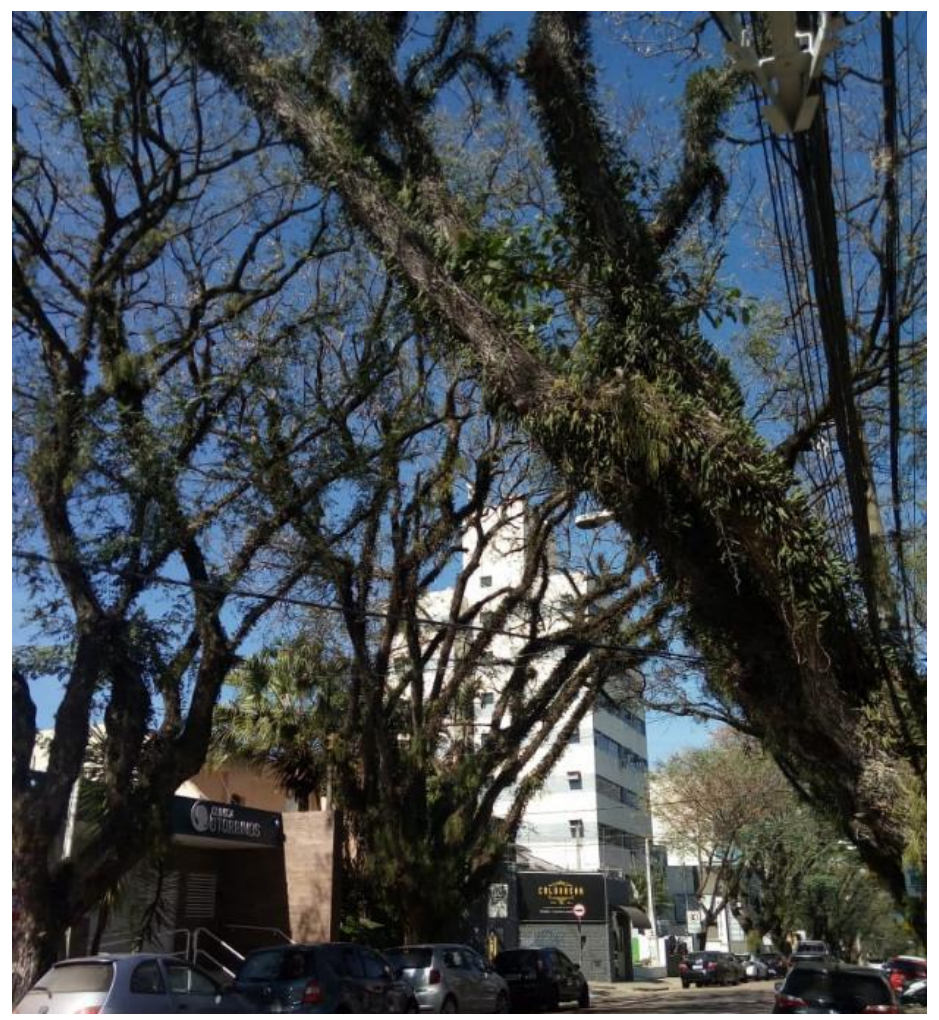

Figura 11. Árvore em conflito com a fiação elétrica

Figure 11. Tree in conflict with wiring

As árvores estudadas apresentaram diferentes circunferências na altura do peito, porém a grande maioria, 70\% (56 indivíduos), possui CAP entre 201 e $500 \mathrm{~cm}$. Entre outros indivíduos analisados destacam-se os 13 indivíduos (16,25\%) que possuem CAP entre 61 e $120 \mathrm{~cm}, 7$ indivíduos (8,75\%) que têm CAP entre 121 e $200 \mathrm{~cm}$ e 4 indivíduos (5\%) que apresentaram CAP entre 1 e $60 \mathrm{~cm}$, estas duas últimas categorias representando árvores mais jovens (Figura 12).

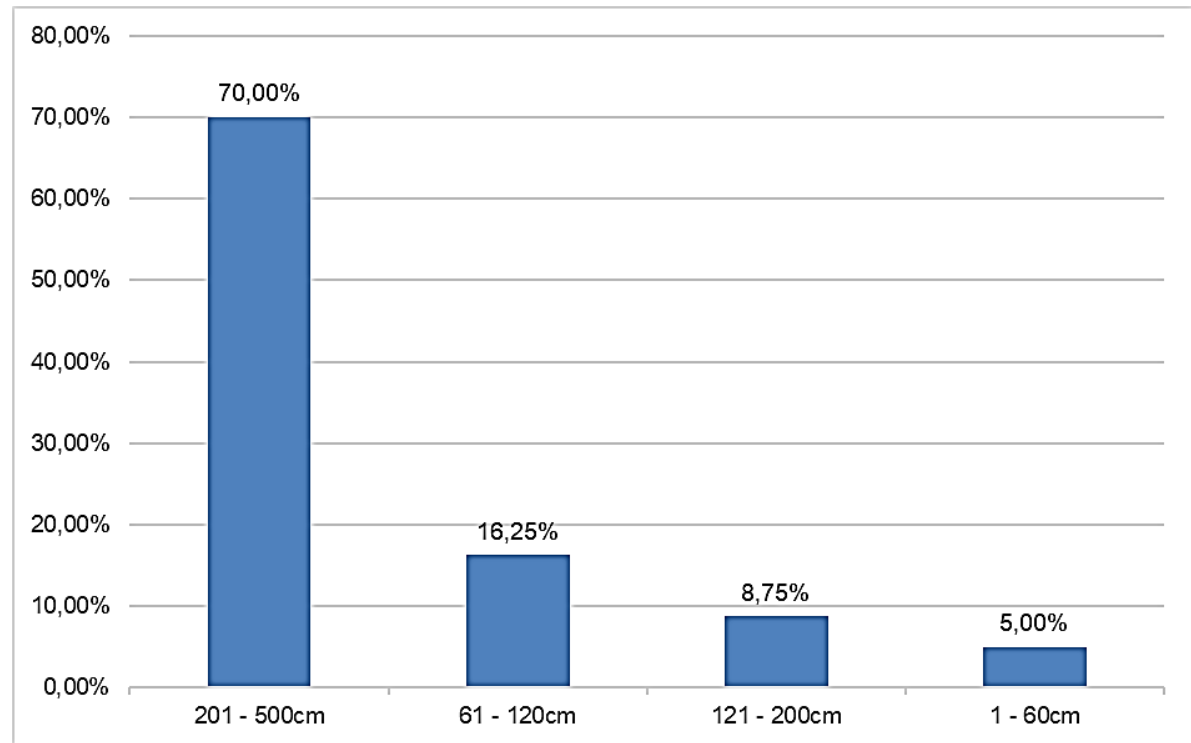

Figura 12. Circunferência na altura do peito

Figure 12. Circumference at breast level 
A avaliação mostrou que a maior parte das árvores da Rua Anchieta em Jundiaí-SP possuem copas bastante grandes. Destaca-se que $57(71,25 \%)$ dos indivíduos avaliados possuem copa com diâmetro superior a 15 metros, 7 (8,75\%) possuem copa com diâmetro entre 10 a 15 metros, 7 (8,75\%) possuem copa com diâmetro entre 7 a 10 metros, 6 (7,50\%) possuem copa com diâmetro de 4 a 7 metros e somente 3 (3,75\%) possuem copa com diâmetro até 4 metros (Figura 13).

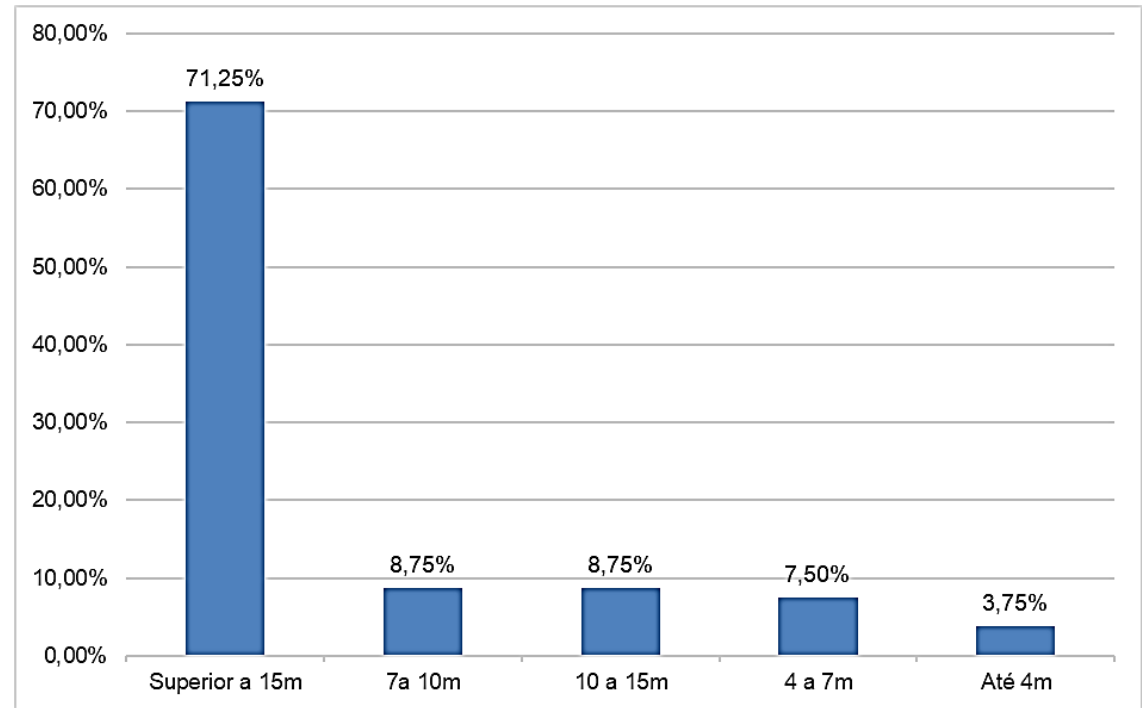

Figura 13. Diâmetro da copa

Figure 13. Canopy diameter

A região estudada apresenta, em sua maioria, árvores bastante altas. Destaca-se que 59 (73,75\%) dos indivíduos analisados têm altura superior a 15 metros, 16 (20\%) têm altura entre 5 e 10 metros, $3(3,75 \%)$ têm altura até 5 metros e $2(2,5 \%)$ têm altura entre 10 e 15 metros (Figura 14).

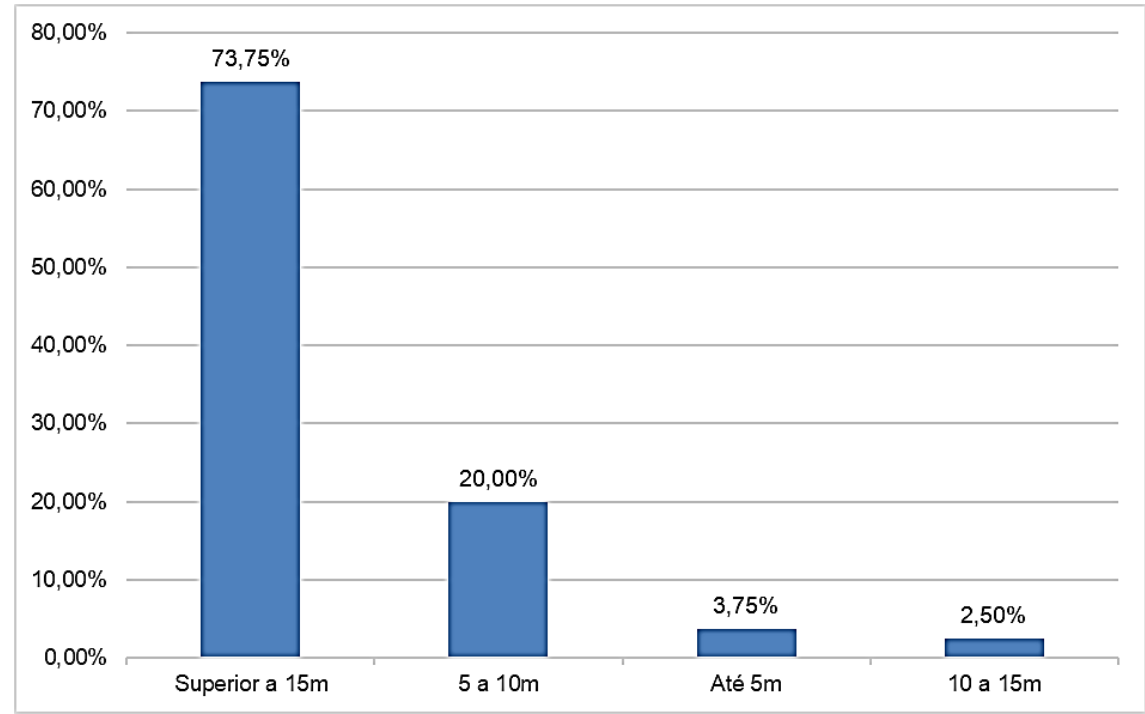

Figura 14. Altura total

Figure 14. Total height 
Em relação à idade das árvores do local, destaca-se que 64 (80\%) dos indivíduos tem idade aparente maior do que 30 anos e que 16 (20\%) tem idade aparente entre 10 e 30 anos (Figura 15).

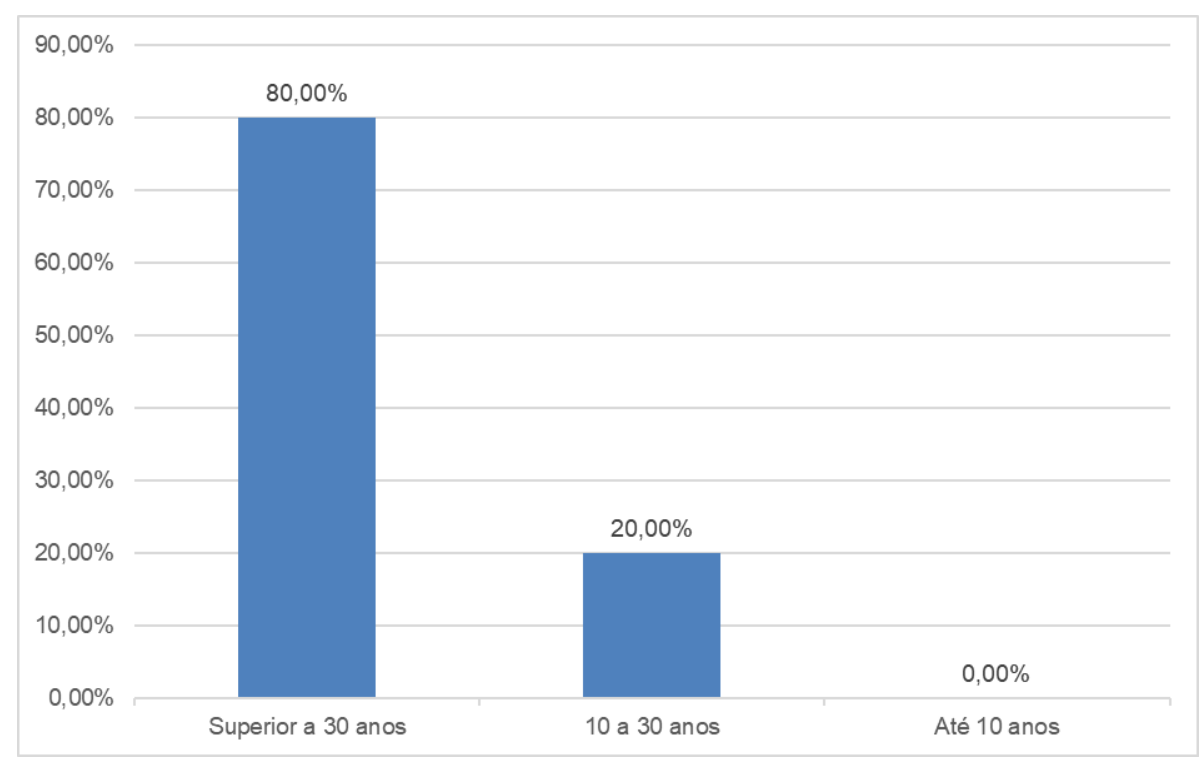

Figura 15. Idade aparente

Figure 15. Apparent age

A grande maioria dos indivíduos arbóreos apresentou CAP superior a $200 \mathrm{~cm}$, bem como copas com diâmetros superiores a 15 metros e altura total superior a 15 metros. Em face do grande porte da maioria dos indivíduos, foi possível inferir que a maioria dos indivíduos têm idade superior a 30 anos, podendo-se considerar uma população arbórea velha em sua maioria. No que se refere à idade aparente, os dados obtidos neste estudo são preocupantes, pois revelam que a maior parte das árvores estudadas possuem idade avançada ou meia idade. Os dados obtidos pelo presente estudo para esse parâmetro se diferenciam bastante do trabalho "Plano Municipal de Arborização Urbana do município de Cabreúva-SP", pois este último revela a presença de muitas árvores jovens no local estudado (CABREÚVA, 2017). Isso revela que na Rua Anchieta em Jundiaí-SP não está ocorrendo um grande esforço para o replantio ou substituição dos indivíduos arbóreos.

De acordo com os dados coletados, 74 (92,5\%) dos indivíduos devem permanecer no local, e 6 dos indivíduos (7,5\%) deveriam ser removidos devido a problemas fitossanitários (figura 16). 


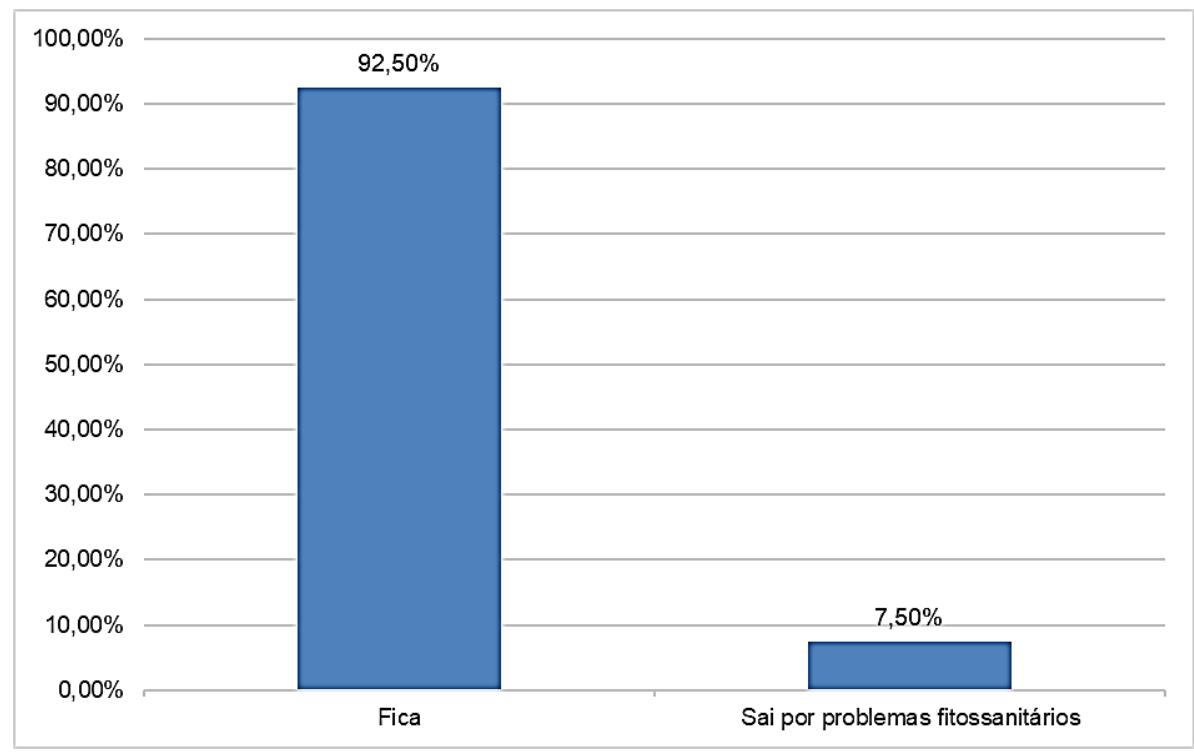

Figura 16. Resultado da avaliação

Figure 16. Results of the evaluation

Diante de todos os parâmetros analisados, foi possível avaliar cada indivíduo como um todo, determinando sua atual situação e estabelecendo se deveria ficar no local ou ser retirado e substituído por um novo individuo arbóreo. A partir dos dados analisados, foi possível concluir que os indivíduos que estão em condições fitossanitárias ruins necessitam de um monitoramento intensivo (a cada seis meses), e 6 dos 80 indivíduos (8\%) que se encontram condenados deveriam ser removidos devido a problemas fitossanitários irreversíveis. Os demais problemas apresentados pelas árvores (conflito com a rede elétrica, problemas na raiz) não caracterizaram a necessidade de remoção destas, já que pequenas intervenções seriam suficientes para minimizar a interferência negativa do indivíduo no local.

No presente estudo, o número de árvores com problemas fitossanitários e que, portanto, precisam ser removidas ou constantemente monitoradas se mostrou bastante alto $(37,5 \%)$, de modo que identifica-se a necessidade de que estas devam sofrer um monitoramento intensivo ou, em alguns casos, supressão.

A arborização urbana exige especificações técnicas e normas para a sua correta implementação e manejo. Para isso, é preciso que cada cidade possua um plano de arborização que contenha um conjunto de métodos e medidas para fazer um manejo correto (GONÇALVES et al., 2018). Dessa forma, se faz necessária a correção dos erros já constatados (como, por exemplo, a implantação de espécies inadequadas, plantio em locais inapropriados, podas malfeitas, entre outros) e a potencialização das ações bem-sucedidas (SCHALLENBERGER et al., 2010). 


\section{CONCLUSÕES}

Por meio da análise dos resultados obtidos no presente estudo, foi possível concluir que as árvores existentes na Rua Anchieta em Jundiaí-SP apresentaram, em sua maioria, um estado fitossanitário regular (compreendendo as espécies Tipuana tipu, Poincianella pluviosa e Ficus benjamina L.). Algumas árvores, porém, se mostraram bastante deterioradas (compreendendo as espécies Tipuana tipu, Poincianella pluviosa, Ligustrum lucidum, Erythrina mulungu e Tibouchina granulosa), indicando a necessidade de remoção das mesmas e substituição por um novo indivíduo de uma espécie mais adequada para aquela área.

Os principais problemas apresentados pelas árvores avaliadas no presente estudo foram cavidades aparentes no tronco, presença de parasitas e raízes expostas.

\section{REFERÊNCIAS}

BRAZOLIN, S.; TOMAZELLO FILHO, M.; YOJO, T.; OLIVEIRA NETO, M. A. D.; ALBUQUERQUE, Á. R.; SETTE JÚNIOR, C. R. Propriedades físico-mecânicas do lenho deteriorado por fungos apodrecedores de árvores de Tipuana tipu. CERNE, Lavras, v. 20, n. 2, p. 183-190, 2014.

CABREÚVA, Secretaria do Meio Ambiente, Obras e Serviços Urbanos. Plano Municipal de Arborização Urbana. Cabreúva: 2017. Disponível em: <https://www.cabreuva.sp.gov.br/ upload/arquivo/0541243001508246794.pdf>. Acesso em 10 mar. 2020.

DOS SANTOS, T. O. B.; LISBOA, C. M. C. A.; DE CARVALHO, F. G. Análise da arborização viária do bairro de Petropólis, Natal, RN: uma abordagem para diagnóstico e planejamento da flora urbana. Revista da Sociedade Brasileira de Arborização Urbana, Piracicaba, v. 7, n. 4, p. 90-106, 2012.

FERRAZ, M. V. Inventário das árvores urbanas da cidade de Registro-SP. Revista da Sociedade Brasileira de Arborização Urbana, Piracicaba, v. 7, n. 2, p. 80-88, 2012.

GONÇALVES, L. M.; DA SILVA MONTEIRO, P. H.; DOS SANTOS, L. S.; MAIA, N. J. C.; ROSAL, L. F. Arborização Urbana: a Importância do seu Planejamento para Qualidade de Vida nas Cidades. Ensaios e Ciência, Londrina, v. 22, n. 2, p. 128-136, 2018.

GOOGLE MAPS. R. Anchieta - Aglomeração Urbana de Jundiaí, Jundiaí - SP: [2020] 1 imagem de satélite, color, 3D. Airbus Digital Globe/Google. Lat. -23.18396206403001, 46.89040369692507. Disponível em: https://www.google.com/maps/. Acesso em: 30 nov. 2020.

JUNDIAÍ - Prefeitura de Jundiaí. Rua Anchieta recebe mutirão de poda de árvore. Jundiaí: 2018. Disponível em: <https://jundiai.sp.gov.br/noticias/2018/12/02/rua-anchieta-recebe-mutiraode-poda-de-arvores/>. Acesso em 31 mar. 2020. 
LORENZI, H. Árvores brasileiras: manual de identificação e cultivo de plantas arbóreas nativas do Brasil. v. 1, 4. ed. Nova Odessa: Instituto Plantarum, 2002. 368 p.

LORENZI, H.; SOUZA, H. M. de; TORRES, M. A. V.; BACHER, L. B. Árvores exóticas no Brasil: madeireiras, ornamentais e aromáticas. Nova Odessa: Plantarum, 2003. 368 p.

MARANHO, A. S.; DE PAULA, S. R. P.; LIMA, E.; DE PAIVA, A. V.; ALVES, A. P.; DO NASCIMENTO, D. O. Levantamento censitário da arborização urbana viária de Senador Guiomard, Acre. Revista da Sociedade Brasileira de Arborização Urbana, Piracicaba, 7, n. 3, p. 44-56, 2012.

MUNEROLI, C. C.; MASCARÓ, J. J. Arborização urbana: uso de espécies arbóreas nativas na captura do carbono atmosférico. Revista da Sociedade Brasileira de Arborização Urbana, Piracicaba, v. 5, n. 1, p. 160-182, 2010.

PINHEIRO, C. R.; SOUZA, D. D. A importância da arborização nas cidades e sua influência no microclima. Revista Gestão \& Sustentabilidade Ambiental, Florianópolis, v. 6, n. 1, p. 67-82, 2017.

SCHALlenBERGER, L. S.; DE ARAUJO, A. J.; DE ARAUJO, M. N.; DEINER, L. J.; DE OLIVEIRA MACHADO, G. Avaliação da Condição de Árvores Urbanas nos Principais Parques e Praças do Município de Irati-PR. Revista da Sociedade Brasileira de Arborização Urbana, Piracicaba, v. 5, n. 2, p, 105-123, 2010.

SZABO, M. S.; DE LURDES FERRONATO, M.; DE SOUZA SILVA, S.; DE SOUZA ALVES, V. K. C. Acessibilidade na arborização urbana na região central comercial de Pato Branco-PR. Revista Técnico-Científica do CREA-PR, Curitiba, v. 5, n. 6, p. 1 -14, 2017.

TOLEDO, D. V.; PARENTE, P. R. Arborização urbana com essências nativas. Boletim Técnico do Instituto Florestal, São Paulo, v. 42, 1988.

TOSCAN, M. A. G.; RICKLI, H. C.; BARTINICK, D.; DOS SANTOS, D. S.; ROSSA, D. Inventário e análise da arborização do bairro Vila Yolanda, do município de Foz do Iguaçu - PR. Revista da Sociedade Brasileira de Arborização Urbana, Piracicaba, v. 5, n. 3, p.165-184, 2010.

ZILLER, S. R. Plantas exóticas invasoras: a ameaça da contaminação biológica. Revista Ciência Hoje, Rio de Janeiro, v. 30, n. 178, 2001. 